\title{
LITERATURA NA COR DA PELE: DISCUTINDO O RECONTO COMO CAMINHO PARA A (RE)CONSTRUÇÃO DA IDENTIDADE DA CRIANÇA NEGRA
}

\author{
LITERATURE BY THE SKIN COLOR: TREATING THE RETELLING AS A \\ SINGULAR WAY TO THE BLACK CHILDREN'S IDENTITY \\ (RE)CONSTRUCTION
}

\section{LITERATURA EN LA PIEL: LA DISCUSIÓN DEL RECUENTO COMO CAMINO PARA LA (RE)CONSTRUCCIÓN DE LA IDENTIDAD DE LOS NINÕS NEGROS}

\author{
Victor André Pinheiro Cantuário ${ }^{1}$ \\ Fabiana Pereira Marques ${ }^{2}$
}

\begin{abstract}
Resumo: O objetivo do artigo é de indicar o reconto a partir da Literatura Infantil Negra (LIN) como instrumento pedagógico favorável para o trabalho de (re)construção da identidade da criança negra. Fazendo-se uso de estudo bibliográfico, buscou-se evidenciar as características que o reconto e a LIN possuem e verificar de que maneira as características daquele não somente atendem às habilidades e competências previstas na Base Nacional Comum Curricular (BNCC), em relação aos anos iniciais do Ensino Fundamental, como de fato pode contribuir para a (re)construção da identidade dos alunos/crianças negros. Por fim, tem-se que ao relacionar o reconto à LIN, o primeiro pode tanto proporcionar o contato direto desses alunos/crianças com as temáticas e os assuntos subordinados a esta quanto permitir que o público em questão se sinta representado em vários contextos de maneira positiva, o que pode resvalar no reconhecimento e autoafirmação de suas identidades.
\end{abstract}

Palavras-chave: Reconto. Literatura infantil negra. Criança. Identidade.

\begin{abstract}
This paper presents the retelling through the Black Children's Literature as a pedagogical resource available to the educational work of black children's identity (re)construction. Using bibliographical sources, it tries to point the retelling and the Black Children's Literature aspects and to see in which ways the characteristics of the first observe what is said in the Base Nacional Comum Curricular, but also can contribute effectively to the (re)construction of black children/students' identity. As conclusion, it is possible to comprehend that to put the retelling and the Black Children's Literature side by side is to open a field where the retelling could be used as a direct channel through which the black children/students make contact with matters fundamental to the self-affirmation of their identities.
\end{abstract}

Keywords: Retelling. Black children's literature. Child. Identity.

\footnotetext{
${ }^{1}$ Doutor em Estudos Literários pela Universidade Estadual Paulista (UNESP). Professor efetivo da Universidade Federal do Amapá (UNIFAP) em Filosofia da Educação. E-mail: ve.cantuario@ gmail.com. ORCID: https://orcid.org/0000-0002-1706-1016.

${ }^{2}$ Graduada em Pedagogia pela Universidade Federal do Amapá (UNIFAP). Especialista em Educação especial e inclusiva pelo Centro Universitário Internacional (UNINTER). E-mail: marquesf896@gmail.com. ORCID: http://orcid.org/0000-0002-2124-5264.
}

Revista de Estudos em Educação e Diversidade. v. 2, n. 6, p. 1-21, out./dez. 2021.

Disponível em: http://periodicos2.uesb.br/index.php/reed

ISSN: $2675-6889$ 
Resumen: El artículo presenta el recuento en conexión con la Literatura Infantil Negra como herramienta pedagógica positiva para el trabajo de (re)construcción de la identidad de los niños negros. Haciendose a partir de libros y otros textos académicos, evidencia las características que tiene el recuento y la Literatura Infantil Negra y también como las características del recuento se armonizan con aquellas competencias inclusas en la Base Nacional Comum Curricular, definidas para la Educación Infantil, en relación a los usos del lenguaje, contribuyendo efectivamente para la (re)construcción de la identidad de los niños/estudiantes negros. La conclusión muestra que poner en contacto el recuento y la Literatura Infantil Negra puede proporcionar una positiva modificación del paisaje educacional y de las cuestiones de identidad aun fuertemente atravesadas por valores culturales esencialmente eurocéntricos.

Palabras-clave: Recuento. Literatura infantil negra. Niños. Identidad.

\section{Introdução}

Este artigo procurou problematizar a ausência de estratégias pedagógicas dentro do contexto escolar para o trabalho com a diversidade étnico-racial, objetivando demonstrar como o reconto e a Literatura Infantil Negra (LIN) se configuram em possível caminho para o trabalho de (re)construção da identidade da criança negra.

Tendo em vista a situação de intolerância e discriminação vivenciada historicamente na sociedade brasileira, põe-se em evidência o uso da palavra (re)construção por se entender que é condição sem a qual não é possível desconstruírem-se visões de intolerância e discriminação e avançar nas considerações significativas de cultura e identidade negra, inclusive nos ambientes formais de ensino.

Ainda a respeito do referido objetivo, pensa-se este em articulação com as oito técnicas da contação de histórias apresentadas por Nunes (2018), bem como com as habilidades e competências da disciplina de Língua portuguesa previstas na Base Nacional Comum Curricular (BNCC) para os anos iniciais do Ensino Fundamental.

O objeto de estudo constrói-se nas características do reconto entendido não apenas como uma modalidade de uso da linguagem, mas também um instrumento pedagógico pelo qual os alunos/crianças, independentemente de cor, gênero ou religião podem externar suas percepções sobre determinado assunto, neste caso, sobre as temáticas étnico-raciais, podendo essas percepções, conforme forem apresentadas, serem problematizadas pelo professor através dos títulos, personagens e enredos que constituem a LIN. O que fortalece a presença desse segmento literário e temático no contexto de sala de aula.

É importante mencionar que a ideia do reconto através da LIN somente foi cogitada a partir do momento em que se observou o potencial pedagógico deste instrumento e o aumento 


\section{Revista de Estudos em Educação e Diversidade}

do número de publicação de livros no segmento do que hoje já se entende como uma literatura infantil e infantojuvenil essencialmente negra.

Deste modo, empresas do ramo editorial como a Mazza Edições e a Pallas Editora têm se dedicado e realizado um trabalho exclusivamente literário a partir de diversas temáticas raciais, visando justamente impulsionar o conhecimento e despertar o pertencimento étnico e identitário em adultos e crianças negros.

Esclarece-se ainda que apesar de o reconto ter sido projetado neste trabalho em conjunto com as habilidades e competências definidas na BNCC para a disciplina de Língua Portuguesa, compreende-se que as suas características podem ser ampliadas ou apropriadas para as finalidades de outras disciplinas que compõem a matriz curricular do nível de ensino em questão, dado o caráter interdisciplinar manifesto por ele. Cabendo aos professores efetuarem as adaptações às finalidades das disciplinas que ministram.

Por fim, sugere-se que a proposta apresentada além de abrir caminho para o combate ao racismo pelas vias da educação, sintoniza-se tanto com os propósitos da Lei 10.639/2003 quanto com as Diretrizes Curriculares Nacionais para a Educação das Relações Étnico-Raciais e com a BNCC, as quais orientam o processo de ensino e aprendizagem e asseguram o trabalho com a história e, sobretudo, com as culturas africana e afro-brasileira, proporcionando o repensar de determinadas ideias a respeito da população negra, de maneira a ampliar as possibilidades de trabalho com temáticas étnico-raciais.

Literatura Negra: algumas considerações sobre o gênero literário

Acredita-se que uma das formas para se promover o trabalho de reconhecimento da identidade negra, em particular no ambiente escolar, é a literatura, em especial a Literatura Negra (LN), haja vista que esta traz em seu bojo o propósito de retratar, a partir múltiplas vertentes, a história de todo um povo atravessado pela eliminação e marginalização passadas e presentes. Por isso, conhecê-la em seu surgimento e estruturação é o ponto de onde se parte.

A historiografia literária brasileira mostra que nem sempre a LN ocupou lugar de considerável visibilidade no cenário da literatura nacional, pois, apesar de sua antiguidade atestada por Souza (2006), a mesma somente ascendeu na medida em que os movimentos feministas e negros articularam-se de modo que suas reivindicações fossem percebidas como temas possíveis de serem incluídos em obras que constituíssem o cânone literário. 


\section{Revista de Estudos em Educação e Diversidade}

Consequentemente, as reivindicações por novos territórios discursivos contribuíram para a formação de um campo de escrita que recebeu denominação própria de Literatura Negra.

Por este motivo, a LN, parte da literatura brasileira, se encontra de maneira indelével marcada e atravessada pelo conjunto de articulações e demandas legais de que se ocupou o movimento negro, já que comunga das mesmas reivindicações historicamente levantadas por este.

Assim, além de ter o negro como tema central de elucidação, objetiva também “desmitificar, resgatar, afirmar [e] emancipar o negro do fantástico véu ideológico que o recobre, mescla, submerge, esconde, ignora" (IANNI, 1988, p. 98), caracterizando uma literatura produzida por sujeitos conscientes etnicamente para outros sujeitos adultos conscientes com a finalidade de desmantelar o discurso em defesa de uma cultura oficial em detrimento de outras possíveis.

Duarte (2020, s.n.) reafirma tal posicionamento ao compreender que a função e a responsabilidade da LN se concentra em agir a favor de temáticas que não possuam amplos espaços para discussão ou que estejam camufladas na aparente igualdade entre indivíduos espraiada socialmente. Quer dizer, a partir do momento que a LN faz uso do seu caráter político, confronta o conservadorismo estético de uma suposta arte pura e denuncia não somente os valores apreciados pela academia em termos de conhecimento e comportamentos, mas um racismo agravado pelo discurso da miscigenação que pôs o negro à margem do corpo social e do campo literário.

Portanto, objetivando a ressignificação do termo negro, na intenção de subverter toda a carga semântica negativa que lhe foi atribuída e levando em conta a afirmação feita por Aimé Césaire (apud DOMINGUES, 2005) de que o movimento da negritude, imbuído de autoafirmação, representou uma revolução tanto na linguagem quanto na literatura, é que se busca evidenciar o termo Literatura Negra por se entender que carrega consigo as individualidades do ser negro em um esforço de autoaceitação, isto é, pode ser usado como expressão consciente do negro que quer criar a si mesmo e que, por isso, particulariza suas produções, dando-lhes características próprias.

Lobo (apud MÉRIAN, 2008) entende que a LN é especialmente a literatura criada por autores negros ou mulatos dentro de um conjunto de significados que evidenciam o pertencimento étnico-racial, bem como o que é ser negro, atrelando à essa discussão fatores de maior amplitude como as religiões de matriz africana, a sociedade e o preconceito, ou seja, é elaborada por um sujeito que se vê e se assume a partir de uma representatividade negra. 


\title{
Revista de Estudos em Educação e Diversidade
}

Em vista disso, nota-se que a LN está intrinsecamente articulada com o imaginário daquele que produz o discurso, encontrando-se em um passeio constante entre presente e passado de modo a fortalecer conteúdos que tomam forma e características distintas, uma vez que a diversidade da escrita literária contribui para que esta se delineie em meio à literatura brasileira, destacando-se pelas suas linguagens e temáticas.

Ao construir uma definição da LN, Ianni (1988, p. 91) demostra em sua escrita essa transitoriedade adquirida pela mesma ao proferir que

\begin{abstract}
[a] literatura negra é um imaginário que se forma, articula e transforma no curso do tempo. Não surge de um momento para o outro, nem é autônoma desde o primeiro instante. Sua história está assinalada por autores, obras, temas, invenções literárias. É um imaginário que se articula aqui e ali, conforme o diálogo de autores, obras, temas e invenções literárias. É um movimento, em devir, no sentido de que se forma e transforma. Aos poucos, por dentro e por fora da literatura brasileira, surge a literatura negra, como um todo com perfil próprio, um sistema significativo.
\end{abstract}

Este perfil próprio mencionado pelo autor surge a partir do avanço em nível nacional dos vários movimentos negros e da Sociedade de Intercâmbio Brasil-África (SINBA), no ano de 1972, quando a LN passou a ocupar lugar de destaque, superando a literatura produzida "sobre o negro", passando a criar uma "literatura do negro para o negro", com particularidades expressivas, sonoras e visuais que a constituem e caracterizam o seu todo literário (LIMA, 2009, p. 72, destaques da autora).

Mesmo assim, é importante dizer que a escrita literária negra se aproxima da chamada literatura comum porque além de se preocupar com as inovações estéticas, obedece à mesma estrutura textual de acordo com o gênero no qual se inscreve, encontrando-se nela um conjunto de cinco elementos fundamentais que certificam, segundo Duarte (2008), a existência da LN, quais sejam: a temática, cujo objeto de escrita é o ser e a vivência negra; na autoria encontra-se a figura, quase que exclusiva, de um autor com a tonalidade da pele escura; o ponto de vista está voltado a entender a cultura, a história e as problemáticas que circundam a sociedade e o objeto de escrita; a linguagem é tomada por uma discursividade com vocabulários e entonações próprias que se entrelaçam ao sentimento de pertença e ressignificação; por fim, destaca-se o público, também negro, que se vê e se quer representado.

Não obstante, Pereira (1995, p. 1035) acredita não serem os critérios étnico e temático a melhor forma de definição desta literatura, pois ao se associarem a obra e o conteúdo à 
origem negra, acaba-se, na percepção dele, produzindo uma "censura prévia" aos autores negros e não negros e, por isso, defende a existência de um "critério pluralista" que possua uma "orientação dialética" capaz de demonstrar a LN "como uma das faces da Literatura Brasileira - esta mesmo devendo ser percebida como uma unidade constituída de diversidades", uma vez que autores não negros produzem conteúdos que interessam aos negros, não deixando o oposto de ser verdadeiro.

Concomitante a isso, Souza (2006, p. 71, destaques da autora) explica que falar de LN pressupõe então duas questões centrais: a primeira é "o lugar de quem fala" seja ele de pertença étnica ou somente de adoção; e a segunda é justamente "um debruçar-se sobre os arquivos da história do negro passada ou presente e/ou sobre as culturas de origem africana" que colaboraram para que essa literatura, inicialmente desprestigiada, em conformidade com as transformações políticas, tecnológicas e sociais abalassem o pedestal do cânone da literatura brasileira.

Deste modo, ressalta-se que do seu próprio lócus de desprestígio "mulheres, afrobrasileiras/os, homossexuais, analfabetos" mobilizaram-se em associação com "a cultura de massa e a cultura popular" para promover uma necessária e provocante investida contra "o campo literário e reivindicaram para si a possibilidade de tematizar, no interior deste campo, questões e problemas sociais e passaram a conferir qualificações de etnia e gênero, por exemplo, à literatura" (SOUZA, 2006, p. 71).

Com isso, percebe-se que os escritores negros, não deixando de falar de si, de suas angústias e alegrias, de fato se sensibilizaram e escreveram passeando por diferentes temáticas, não podendo seus textos, de forma alguma, serem reduzidos e nem limitados apenas a um eixo de composição literária.

A partir do exposto, Duarte (2008) demonstra que antes de avaliar e classificar uma obra é necessário atentar-se para o ponto de vista, pois é ele que, articulado com o conjunto de valores e crenças, revelará as intenções propostas pelo autor, evitando-se, de todo modo, determinadas reduções temáticas e sociológicas da LN à cor da pele ou à condição social.

Percebe-se que a principal motivação dos autores que se comprometem com LN, nos dias de hoje, é a denúncia de um racismo e de um etnocentrismo que excluem homens, mulheres negros e afrodescendentes, estendendo-se a um processo de ressignificação, ascensão, reconhecimento e valorização de uma identidade individual e coletiva, uma vez que carregam como desígnio uma conscientização e uma reeducação das relações étnico-raciais da sociedade brasileira. 


\section{Revista de Estudos em Educação e Diversidade}

É importante perceber, nessa linha de pensamento, que a LN é, antes de mais nada, uma forma de arte, a qual carrega consigo mais a expressividade "de um $e u$ enunciador que se quer negro", como afirma Bernd (1988, p. 22, destaque da autora), e, por isso, experimenta diretamente as consequências da discriminação, do que a expressão literal de autores negros escrevendo para um público "idêntico" a si, como se estivesse em jogo, no caso de autores não negros, a própria existência dessa literatura, ou seja, na contramão de posturas reducionistas, a LN amplia-se em todos os sentidos possíveis quanto aos temas, autores e perspectivas.

Assim, os temas tratados na LN passam a alcançar todas as faixas etárias, adquirindo autoridade em novos campos como é o caso da Literatura Infantil que integra agora em seu corpus literário uma dimensão chamada Literatura Infantil Negra (LIN), a qual se volta a atenção por se perceber que ela carrega em seu bojo problemáticas referentes ao ser negro, mostrando-se caminho proveitoso para que seja possível a efetivação de um trabalho de desconstrução de quaisquer formas de preconceito que venham ser praticadas e vivenciadas por crianças, pois, conforme Paiva, Nunes e De Deus (2010), essas crianças, ao darem início à vida escolar, já possuem um conjunto de crenças e noções previamente estabelecidas que podem levá-las a assumir determinadas posturas resultantes do meio familiar e social.

Os autores, embasados em uma perspectiva vigotskiana, demonstram que as "ideias da criança a respeito do mundo são construídas a partir da sua relação com o meio e se modificam à medida que os conhecimentos são construídos", sendo possível entender que aquilo que o sujeito experimenta nas relações interpessoais pode ser "internalizado, (re)apropriado, ou (re)construído, causando modificações na [sua] própria estrutura psíquica" (PAIVA; NUNES; DE DEUS, 2010, p. 89).

Pautado nisso, entende-se que a formação histórico-social do Estado brasileiro deixou vestígios negativos nas relações humanas quando rebaixou determinados grupos étnicos ao processo de exploração e miséria social e que esses vestígios, ao serem reproduzidos e compartilhados, subvertem-se e internalizam-se na mentalidade daqueles ainda desprovidos de criticidade, dado o fato de se encontrarem em processo de desenvolvimento da consciência. Por esse motivo, admite-se que o trabalho com a Literatura Infantil Negra e o reconto é eficaz no processo de esclarecimento e adequação da linguagem sobre o assunto à criança, tornandose necessário explorá-los e pretender caracterizá-los apropriadamente. 


\section{Revista de Estudos em Educação e Diversidade}

Uma literatura na cor da pele: a caracterização da Literatura Infantil Negra

Diante do desafio particular de mostrar que a discriminação pela cor da pele existe e se reproduz socialmente nos comportamentos e hábitos linguísticos nos mais variados espaços, inclusive o escolar, fazendo com que crianças negras neguem sua identidade e seu pertencimento étnico-racial, tem se consolidado nas últimas décadas uma literatura voltada ao público infantojuvenil, comprometida com a tarefa de problematizar, expor e contribuir para a desconstrução de paradigmas preconceituosos e a falta de percepção da multiculturalidade, qual seja, a Literatura Infantil Negra (LIN).

Dá-se atenção para esta literatura porque se entende que tanto ela quanto a LN podem ser pensadas como contraliteratura (MOURALIS apud BERND, 1988) que procuram questionar a literatura de cunho eurocêntrico em um esforço de escrever novamente através de um olhar politizado e consciente a história e o universo do ser negro, com o objetivo de remodelar um cenário dominado por tendências literárias majoritariamente europeias ou marcadas pela tônica do branqueamento.

Em vista disso, ambas as literaturas têm se empenhado na busca de argumentos que possam ser agregados à literatura brasileira de maneira a contribuir com um desejo latente do ser negro de realizar "sua própria leitura e interpretação do mundo" (BERND, 1988, p. 26).

A respeito da origem da LIN, observam-se semelhanças e diferenças desta com a Literatura Infantil. Em relação às semelhanças, nota-se que ambas têm seu surgimento atrelado às "narrativas orais que, originalmente, não eram destinadas à infância, mas à sociedade como um todo" (CAMPOS, 2016, p. 58).

Já as diferenças estão no fato de que enquanto os primórdios da Literatura Infantil se reportam à tradição oral de países ocidentais como a França, a Alemanha e a Dinamarca, os da LIN remontam ao Oriente, mais especificamente "a algumas regiões da África onde a preservação e transmissão da cultura amparava-se na oralidade" (CAMPOS, 2016, p. 58). Tais preservação e transmissão dessas narrativas tinham como referência a figura dos Griôs ${ }^{3}$ tradicionais contadores de histórias.

A LIN, apesar de compor hoje o corpus da Literatura Infantil, nem sempre, na história da literatura infantojuvenil brasileira, ocupou lugar de prestígio. Na verdade, após sofrer um

\footnotetext{
3 Os Griôs eram considerados bibliotecas vivas, acervo coletivo, comunicadores da tradição oral e patrimônio cultural. Cabia a eles o papel de coletar, preservar, transmitir e retransmitir às gerações posteriores os saberes, mitos e lendas seculares coletados no contexto das diversas aldeias e tribos africanas. Em razão disso, sua figura e sua importância para a manutenção da tradição oral também passam a ser representadas na LIN (SILVA, 2012).
}

Revista de Estudos em Educação e Diversidade. v. 2, n. 6, p. 1-21, out./dez. 2021.

Disponível em: http://periodicos2.uesb.br/index.php/reed

ISSN: $2675-6889$ 
apagamento constante teve de reivindicar o seu espaço na produção desta literatura, uma vez que os seus pioneiros aqui no país além de se encontrarem imersos em um contexto de época marcado pela tônica do discurso colonial, acabavam por não retratar de igual maneira o seu público: as crianças negras.

Deste contexto para cá, mudanças graduais de natureza temática, estilística, estrutural e de orientação ideológica foram acontecendo no corpus dessa literatura. Contudo, essas mudanças, em vez de contribuírem para que a criança negra reconhecesse sua identidade individual e seu vínculo cultural, contrariamente, encaminharam um processo de negação, sendo possível afirmar que os contornos da LIN, em relação à Literatura Infantil, aparecem somente a partir da produção de Monteiro Lobato. ${ }^{4}$

Castilho (2004, p. 110) atesta que despontaram, posteriormente, vários estudos advindos de membros da comunidade acadêmica articulados com representantes dos movimentos negros que resultaram no surgimento de autores com novas propostas de obras literárias para o público infantil, as quais procuraram "romper com um imaginário estereotipado do negro tão comum na literatura infanto-juvenil até então”.

A partir disso, as mesmas temáticas já compartilhadas na LN para adultos são incorporadas à Literatura Infantil e colocadas em evidência para as crianças, fazendo surgir a LIN, entendida por Campos (2016, p. 55) como o "conjunto de obras literárias produzidas para a infância que apresenta como tema central aspectos das histórias e cultura dos povos negros, seja na diáspora ou no continente africano", a qual tem contribuído significativamente para a escritura dos novos caminhos da história daquele que é seu objeto principal.

Por conta desta movimentação, é possível afirmar com base em Lima (2009) que hoje existe uma literatura do negro para o negro e não sobre o negro como antes era produzida. Já existe e se pode falar também, principalmente a partir dos anos $2000^{5}$, de uma literatura infantil totalmente negra com enredos e características próprias que colocam os seus

\footnotetext{
${ }^{4}$ Em torno de Lobato, segundo Moraes (1997) e Lajolo (1998), orbitam duas tendências de análise, cada uma buscando sentenciar a que de fato sua obra se propôs. De um lado, aproximadamente até os anos de 1970, ele é descrito como autor engajado e preocupado com a persistência da divisão entre indivíduos na sociedade brasileira de sua época, portanto, um Lobato denunciando o racismo contra os negros no Brasil. De outro, a partir de 1980, tem-se nas leituras de revisão de seus escritos a percepção de um Lobato mais preocupado com a arte da escrita, apenas pintando a sociedade na qual viveu, sociedade que compartilhava da moda importada do continente europeu, apoiada numa leitura equivocada do darwinismo que não apenas propunha a diferença entre indivíduos como rebaixava o homem negro na divisão de classes, defendendo uma hierarquia na qual ele estaria em posição inferior aos demais.

5 Após a publicação da Lei n. 10.639/2003, surgiram ações afirmativas voltadas para a valorização da diversidade étnico-racial no contexto escolar, requerendo-se mudanças no acervo de livros didáticos a serem adquiridos pelas escolas brasileiras por meio dos programas nacionais como o PNLD e o PNBE, o que pode justificar o aumento na produção de livros a partir da temática em questão (CAMPOS, 2016).
}

Revista de Estudos em Educação e Diversidade. v. 2, n. 6, p. 1-21, out./dez. 2021.

Disponível em: http://periodicos2.uesb.br/index.php/reed

ISSN: $2675-6889$ 
personagens no centro da discussão, delegando a estes os papéis de protagonistas como o que vêm produzindo as Editoras Mazza e Pallas ${ }^{6}$ (GOMES JUNIOR, 2014; CAMPOS, 2016; PEREIRA, 2016; JOVINO, 2017).

Nestas obras, os personagens estão colocados como enunciadores de suas próprias histórias, uma vez que o objetivo principal consiste em trabalhar, impreterivelmente, questões relativas ao reconhecimento das representações simbólicas materiais e imateriais que caracterizam a identidade deste grupo étnico, buscando constantemente a criação e a consolidação de um eixo de referência essencialmente negro, de modo a desconstruir o racismo reproduzido historicamente nas diversas instituições sociais que tentaram extinguir as expressões negras através da lógica do apaziguamento.

Os traços mais presentes e observáveis na LIN têm se comprometido a enaltecer as vivências negras de modo a visibilizar e destacar as histórias orais de origem africana. Percebe-se também um processo de ressignificação das personagens negras quando estas deixam de representar papéis subordinados de empregadas e passam a ocupar outros espaços socialmente reconhecidos.

Nesta perspectiva, para Jovino (2006, p. 189), "elas passam a ser personagens principais, cujas ilustrações se mostram mais diversificadas e menos estereotipadas, fugindo da representação do primeiro momento, em que aparecia [sic] sempre de lenço e avental”.

Alguns livros ${ }^{7}$ como A cor da ternura de Geni Guimarães, Betina de Nilma Lino Gomes e Mãe Dinha de Maria do Carmo Galdino procuram estabelecer analogias temporais entre passado e presente para melhor explicar o processo histórico vivenciado pela população negra. Com isso, valendo-se da resistência e dos aspectos culturais cultivados há séculos por homens e mulheres escravizados, passam a retratar as personagens nas histórias de forma a percorrer o caminho entre a infância e a fase adulta, principalmente, para evidenciar o processo de reconhecimento com a identidade negra.

A beleza e a estética negra adquirem ênfase nessas obras. Assim, diferente da beleza com traços brancos muito absorvidos na primeira metade do século XX pela Literatura Infantil, as personagens começam a ter enredos e personalidades próprios, sendo apresentadas na maioria das vezes com tranças, cabelos volumosos, crespo, dreads e outros penteados e vestimentas diversas.

\footnotetext{
${ }^{6}$ Os exemplares de ambas as editoras podem servir de indicação às equipes pedagógicas e aos professores das escolas que tenham interesse em realizar o trabalho com o reconto da forma como se está propondo.

${ }^{7}$ Os títulos citados ao longo dessa seção provêm tanto de consulta ao trabalho de Jovino (2006) quanto de pesquisa on-line realizada durante levantamento bibliográfico para a escritura deste artigo.
}

Revista de Estudos em Educação e Diversidade. v. 2, n. 6, p. 1-21, out./dez. 2021.

Disponível em: http://periodicos2.uesb.br/index.php/reed 


\section{Revista de Estudos em Educação e Diversidade}

Tais aspectos são possíveis de se observar nas obras Bruna e a galinha d'angola de Gercilga de Almeida, $O$ cabelo de lelê de Valéria Belém, Menina bonita do laço de fita de Ana Maria Machado, As tranças de Bintou de Silviane Diouf, O mundo no black power de Tayó de Kisuam Oliveira, Meu crespo é de rainha de Bell Hooks e Chico juba de Gustavo Gaivota.

Os enredos dessas histórias passeiam por narrativas diferentes. Enquanto uns apresentam e problematizam a discriminação e o preconceito patentes no ambiente escolar, sustentando o estranhamento pelos alunos/crianças negros de suas identidades, haja vista que as referências positivas do negro nesse espaço são poucas ou inexistentes, outros preferem destacar, indo além dos estereótipos, príncipes, princesas e heróis negros, o resgate e a ressignificação dos valores simbólicos, a beleza da fauna, da flora, dos costumes, das tradições, dos mitos e lendas característicos dos povos que habitam o continente africano, bem como as suas contribuições na diáspora.

Deste ponto de vista, Jovino (2006, p. 216) ressalta que existem livros

que retomam traços e símbolos da cultura afro-brasileira, tais como as religiões de matrizes africanas, a capoeira, a dança e os mecanismos de resistência diante das discriminações, objetivando um estímulo positivo e uma auto-estima favorável ao leitor negro e uma possibilidade de representação que permite ao leitor não negro tomar contato com outra face da cultura afro-brasileira que ainda é pouco explorada na escola, nos meios de comunicação, assim como na sociedade em geral.

Enredos como os das obras Todas as cores do negro de Arlene Holanda, Minha mãe é negra sim! de Patrícia Santana, Omo-Oba histórias de princesas de Kiusam de Oliveira, A história do rei Galanga de Claudiane Sales, Obax de André Neves, Meninas negras de Madu Costa, Um safári na Tanzânia de Laurie Krebs e $O$ que há de África em nós de Wlamyra Albuquerque e Walter Fraga têm buscado mostrar uma outra representação do negro que se afasta completamente das visões deturpadas atribuídas a ele e à sua cultura, pretendendo desconstruir concepções divulgadas tanto nas mídias sociais quanto pela literatura clássica acadêmica de uma África como lugar de guerras, canibalismo, miséria e epidemias.

Assim, as manifestações do corpo, do cabelo, da dança, da religião, dos mitos, das lendas e tradições que constituem o acervo da LIN não demonstram somente a verdadeira força da arte negra, mas encontram nesta um lugar de continuação, esclarecimento e valorização dessas manifestações no imaginário dos alunos/crianças/leitores, visto que a ligação dessas temáticas às funções lúdicas presente na literatura para crianças, como o 


\section{Revista de Estudos em Educação e Diversidade}

fantástico, transporta esses sujeitos para um mundo relativamente fictício na tentativa de conversar sobre situações sérias e reais.

Por esses motivos, compreende-se que tal literatura pode auxiliar o trabalho do professor com o reconto. Entretanto, o fato de se ter editoras especializadas na temática étnico-racial não dispensa o cuidado daquele no momento de selecionar os livros com os quais pretende desenvolver atividades, pois a seleção das histórias para o trabalho com os alunos/crianças deve atender a critérios pedagógicos, estruturais e éticos.

Dessa forma, as histórias selecionadas pelo professor não devem conter

palavras de baixo calão, e nem termos demasiadamente difíceis ou pejorativos, nem que ensejem preconceito ou violação de leis, visto que sua formação está em voga. Para despertar a atenção da criança e prendê-la, a contação de histórias precisa ser bem estruturada e instigar a curiosidade (NUNES, 2018, p. 33).

Para finalizar, se o professor pretende trabalhar a história do negro na diáspora, poderá selecionar obras que retratem a nostalgia, a memória, a preservação dos laços e a resistência. Mas caso queira enfatizar a história do negro no tempo presente, terá de selecionar obras que apresentem o resgate como significação, “como valorização de um legado, como reivindicação de uma participação na formação da identidade cultural brasileira" e como cidadãos reconhecidamente de direitos (SILVA, 2012, p. 316).

\section{Recontar histórias para (re)construir identidades}

Historicamente, a educação brasileira encontra-se orientada por ideologia de caráter eurocêntrico, a qual escancara aos olhos de quem quiser reflexos de um país colonizado por brancos conservadores, tal que, ao se adentrar nos espaços formais de ensino, se observa a existência de um único modelo ideal de sociedade, rebaixando à função de coadjuvante ou mesmo ao ponto de ser perder de vista as participações e contribuições dos outros grupos étnico-raciais na estruturação da sociedade brasileira.

Nesse contexto, é inevitável não se concordar com Gomes Junior (2014, p. 8) quando sinaliza que a escola, impregnada pela nocividade daquele caráter ideológico, reproduziu e tornou-se sustentação de uma "sociedade marcada por silenciamentos" resultantes diretamente da imposição vocal e estética de uma matriz social que se construiu e se pôs como superior, ainda que não seja. 


\section{Revista de Estudos em Educação e Diversidade}

Apesar das decisões tomadas nas políticas educacionais atualmente, em especial aquela referente à Lei 10.639/2003, que resguardou a todos o direito de acesso a diferentes fontes da cultura nacional brasileira, dentre elas as das histórias e culturas africana e afrobrasileira, o currículo escolar ainda é visto como lugar no qual as relações de poder continuam evidenciando as culturas de origem europeia, pontuando de maneira rasa ou não dando espaço para o tratamento das culturas africana e afro-brasileira ou de outras matrizes que se afastem daquela.

Nesse tom, Silva (2002, p. 35) comenta que o "currículo da escola está baseado na cultura dominante: ele se expressa na linguagem dominante, ele é transmitido através do código cultural dominante", tornando-se incompreensível e estranho para as crianças das ditas classes dominadas.

Esse currículo escolar produz condições profundamente contrastantes, pois enquanto as crianças oriundas das classes "dominantes" são muito bem favorecidas no contexto escolar, alcançando os níveis superiores do sistema educacional, as crianças das classes "dominadas" encaram e convivem constantemente com o fracasso, pois ao contrário daquelas, tem sua "cultura nativa desvalorizada, ao mesmo tempo que seu capital cultural, já inicialmente baixo ou nulo, não sofre qualquer aumento ou valorização" (SILVA, 2002, p. 35).

Este cenário somente reforça o fato que se vem problematizando, o de que as crianças negras, assim como os outros alunos/crianças pertencentes às classes "dominadas", por não terem a identidade, a cultura e a história de seus antepassados representadas no currículo escolar, acabam sendo excluídos e, ao mesmo tempo, absorvidos pela cultura que os explorou e os colocou em situação de subalternidade.

Atentando para esses pressupostos, com a intenção de construir estratégia pedagógica para o trabalho com a Educação para as Relações Étnico-Raciais e para o Ensino de História e Cultura Afro-brasileira e Africana ${ }^{8}$ em perspectiva crítica, assume-se que o reconto e a LIN não se configuram somente em uma importante via para que a identidade da criança negra venha a ser (re)construída e representada no currículo escolar, mas instrumentos de uso pedagógico que confrontam a ideologia mencionada inicialmente através do contato e da

\footnotetext{
${ }^{8}$ A Resolução n. 01/2004 instituiu as Diretrizes Curriculares Nacionais para a Educação das Relações ÉtnicoRaciais e para o Ensino de História e Cultura Afro-brasileira e Africana, definindo em seu art. $2^{\circ}$, $\S 1^{\circ}$, que o objetivo destas consiste na "divulgação e produção de conhecimentos, bem como de atitudes, posturas e valores que eduquem cidadãos quanto à pluralidade étnico-racial, tornando-os capazes de interagir e de negociar objetivos comuns que garantam, a todos, respeito aos direitos legais e valorização de identidade, na busca da consolidação da democracia brasileira" (BRASIL, 2004, p. 1).
}

Revista de Estudos em Educação e Diversidade. v. 2, n. 6, p. 1-21, out./dez. 2021.

Disponível em: http://periodicos2.uesb.br/index.php/reed

ISSN: 2675-6889 


\section{Revista de Estudos em Educação e Diversidade}

leitura de livros prenhes de explicações que se propõem a apresentar aos alunos/crianças uma outra visão de mundo.

O reconto, assim como a origem da LIN, está calcado fortemente na oralidade e faz uso constante da capacidade oferecida ao indivíduo pela memória de recordar o que ouviu, por isso, o que se sobressai no ato de recontar é o resgate do enredo e dos pontos que mais chamaram a atenção do ouvinte.

É justamente nessa característica principal do reconto que se acredita estar o potencial pedagógico deste instrumento em conjunto com a LIN, pois os alunos/crianças, ao ouvirem e trabalharem com a história, conseguem perceber as características e os elementos desta e, ao se identificarem com esses elementos, passam a se apropriar deles, criando uma narrativa própria (reconto), os quais podem ser incorporados não somente na sua constituição de alunos/crianças em sala de aula, mas também na de sujeitos sociais.

Ao se configurar como um contar de novo, o reconto impõe como circunstância para sua efetivação um contar primeiro, o que quer dizer, antes de haver o reconto, tem de haver um contar, um ler que se fundamente como ponto de partida, o que se pode chamar de momento zero.

Nunes $(2018$, p. 28) reforça que "para cada criança a contação de histórias produz efeitos únicos e personalizados ativando diferentes afetos, de acordo com os referenciais e conhecimentos de cada uma", e completa dizendo que cada história com a qual a criança tem contato acaba por formar uma base de conhecimentos que imbricados às suas vivências fomentam a criação de narrativas próprias, o que certamente reflete um amadurecimento intelectual, um olhar mais consciente e ampliado para o mundo.

Ao se pensar nas particularidades da leitura, palavra escrita, e da contação, palavra oral, finda-se por encontrar um dos fundamentos sobre o qual se assenta o reconto e esse mesmo fundamento vem servindo de base de sustentação para o ato da contação.

Sobre esse quesito, Matos e Sorsy (2009, p. 9) expressam o seguinte:

O grande segredo dos bons contadores está na perfeita assimilação daquilo que pretendem contar. Assimilação no sentido de apropriação. Apropriar-se de uma história é processá-la no interior de si mesmo. É deixar-se impregnar de tal forma por ela que todos os sentidos possam ser aguçados e que todo o corpo possa naturalmente comunicá-la pelos gestos, expressões faciais e corporais, entonação de voz, ritmo etc. 


\section{Revista de Estudos em Educação e Diversidade}

Portanto, há nos atos da contação e do reconto aspectos compartilhados que permitem associá-los a condições sem as quais não seriam possíveis: a necessidade da escuta, ou seja, de um ouvido atento ao que está sendo narrado a fim de que não se percam detalhes importantes do enredo e da história em si. A assimilação como força impulsionadora de ambos os atos que contribui para o seu surgimento e desenvolvimento, porque sem conhecimento do que se está contando ou recontando torna-se inviável a recriação de uma experiência.

Além desses dois aspectos ainda desponta mais dois, quais sejam, a capacidade de selecionar elementos e realizar analogias para que o narrador possa transmitir aos seus ouvintes uma versão da história em questão, que sempre há de ser a sua versão. E a memória que opera a função de reunir os aspectos anteriores e pô-los em contato, pois o contar e o recontar pressupõem a capacidade de recordar conteúdos, mensagens, enredos e experiências de modo a adaptá-los à voz do narrador.

Daí dispõe-se o entendimento de estarem vinculadas à ideia do reconto percepções de mundo particulares, pois envolvem sujeitos sociais distintos advindos de constructos sociais e culturais variados, ainda que se encontrem no mesmo ambiente físico de vivência ou pertençam à mesma comunidade. Isto quer dizer que uma aliança de sentidos e interpretações se faz necessária para viabilizar o êxito que se busca.

Tal êxito terá possibilidade de se realizar a contento se no ambiente de ensino for dada devida visibilidade ao desenvolvimento do letramento como instrumento de trabalho com os alunos/crianças, a partir do qual se pretende não apenas que saibam decodificar as letras e seus sons, mas sejam efetivamente capazes de compreender, ao interpretar conteúdos escritos ou orais, os sentidos daquilo que por vezes não está exposto.

Vale frisar que as práticas de letramento através da LIN e do reconto podem ser fomentadas em todas as disciplinas da matriz curricular do primeiro segmento da educação básica, visto que a Base Nacional Comum Curricular (BRASIL, 2018) dá abertura para tal trabalho. No entanto, trata-se aqui do reconto e da LIN conforme trabalho a ser desenvolvido a partir da disciplina de Língua Portuguesa porque, ao consultar as habilidades e competências desta para os anos iniciais de Ensino Fundamental na BNCC, percebe-se como se mostram viáveis ao desenvolvimento da proposta que se vem pondo em foco.

De modo a se tornar evidente a relação entre o reconto e as competências e habilidades da Língua Portuguesa definidas na BNCC, apresentam-se, conforme se pode verificar a seguir, oito das doze técnicas de contação reunidas por Nunes (2018, p. 31). 


\section{Revista de Estudos em Educação e Diversidade}

REED

Tais técnicas possuem um caráter abrangente no sentido de poderem ser dimensionadas também para o trabalho com o reconto e, por terem essas características, acabam correspondendo àquilo que se pretende quanto à externalização pelos alunos/crianças, após a contação, de suas percepções em relação às temáticas étnico-raciais contidas nas obras desse subgênero literário.

1) Histórias com comandos: durante a contação da história professor e alunos/crianças escolherão comandos (palmas, danças, risadas, assovio) para executarem conforme a aparição de uma passagem, de um ou mais personagens da história trabalhada.

2) Histórias com participação da criança: os alunos/crianças participam da história a ser contada auxiliando o professor, representando um personagem, por exemplo.

3) Histórias com onomatopeias: os alunos/crianças executam os sons que por ventura venham a ser feitos pelos personagens da história para caracterizá-los.

4) Histórias com gestos: os gestos ligados às falas da história ou dos personagens são representados pelos alunos/crianças.

5) Técnica da história incompleta: o professor realiza a contação da história normalmente, porém, o desfecho da história fica a cargo dos alunos/crianças, cada um dará o final desejado àquela.

6) Técnica da história continuada: o professor inicia uma história, com apoio de um livro ou não, e os alunos/crianças da turma vão dando continuidade à história de modo a construir um início, meio e fim para ela.

7) Técnica do traço: os alunos/crianças delineiam um traço, com base neste compõem um desenho inteligível, deste desenho pensam em uma história e a escrevem, posteriormente, reúnem o desenho e a história com a de outro colega verificando o resultado, ambos reunirão os seus desenhos e história com a de uma outra dupla de colegas. Essa sequência de junção dos desenhos e histórias segue até que se consiga juntar todas as crianças da turma, formando uma única história.

8) Técnica do reconto da história: os alunos/crianças após escutarem a história, poderão recontá-la por via oral ou escrita à sua maneira. Neste processo, estão à vontade para personalizar suas falas, expressar sentimentos e ideias, acrescentar elementos de sua realidade e vivências.

Essas técnicas podem ser agrupadas conforme o nível de dificuldade que apresentam para sua realização, quer dizer, algumas delas demonstram um menor grau de complexidade como as histórias com comandos, histórias com participação da criança, histórias com 


\section{Revista de Estudos em Educação e Diversidade}

onomatopeias e histórias com gestos, já as técnicas da história incompleta, da história continuada, a técnica do traço e a técnica do reconto da história incorporam o grupo de maior complexidade.

Portanto, atendendo às características dos alunos/crianças de acordo com o nível de ensino em discussão, percebe-se que as técnicas consideradas de menor complexidade, podem ser utilizadas pelo professor para iniciação ou preparação das crianças para o reconto, uma vez que exigem delas, quase que exclusivamente, uma participação simbólica.

As técnicas de maior complexidade, por outro lado, podem ser vistas não mais como um processo de iniciação e sim de desenvolvimento para o reconto em si, posto que ao passar para este grupo os alunos/crianças começam a atuar com um nível maior de protagonismo, momento em que além de exercitarem a imaginação e a criatividade, fazendo constantemente uso da memória, leem, produzem e reproduzem continuamente interpretações sobre variados assuntos, no caso em questão, sobre a temática da diversidade étnico-racial.

Considerando as características do reconto apresentadas anteriormente e de cada uma das oito técnicas, entende-se que o professor conseguirá fazer com que os alunos/crianças desenvolvam as habilidades da Língua Portuguesa contidas na BNCC que versam sobre a comunicação, leitura, escrita, revisão e produção de textos, tais como pode se observar:

EF15LP06 - Reler e revisar o texto produzido com a ajuda do professor e a colaboração dos colegas, para corrigi-lo e aprimorá-lo, fazendo cortes, acréscimos, reformulações, correções de ortografia e pontuação.

EF15LP07 - Editar a versão final do texto, em colaboração com os colegas e com a ajuda do professor, ilustrando, quando for o caso, em suporte adequado, manual ou digital.

EF15LP09 - Expressar-se em situações de intercâmbio oral com clareza, preocupando-se em ser compreendido pelo interlocutor e usando a palavra com tom de voz audível, boa articulação e ritmo adequado.

EF15LP19 - Recontar oralmente, com e sem apoio de imagem, textos literários lidos pelo professor. (BRASIL, 2018, p. 95)

Em vista disso, o professor, aprimorando a utilização das técnicas apresentadas, em especial a do reconto de histórias, conseguirá problematizar e refletir com os alunos/crianças sobre os temas de que tratam os títulos, enredos e histórias que compõem o acervo da LIN.

É neste momento, acredita-se, que está o processo transformador no qual há de se dar a (re)construção da identidade dos alunos/crianças negros, pois o contato aproximado com essa literatura a partir do reconto há de torná-los mais conscientes literária, política e socialmente, haja vista que o conhecimento ampliado sobre a história e as culturas africana e 


\section{Revista de Estudos em Educação e Diversidade}

afro-brasileira encadeia-se no próprio reconhecimento e pertencimento por parte destes alunos/crianças ao seu grupo étnico-racial. O que de certa forma pode os impulsionar desde já o enfrentamento das desigualdades impostas com base na cor da pele.

O trabalho com o reconto atende ainda a algumas competências previstas na BNCC para a disciplina de Língua Portuguesa, o que permite não somente o seu desenvolvimento dentro de sala de aula, mas também da questão da diversidade, já que tais competências se relacionam com esta temática.

A título de exemplo, citem-se a compreensão da "língua como fenômeno cultural, histórico, social" e como um "meio de construção de identidades de seus usuários e da comunidade a que pertencem"; o reconhecimento dos textos "como lugar de manifestação e negociação de sentidos, valores e ideologias" e o ato de "ler, escutar e produzir textos orais, escritos que circulam em diferentes campos de atuação e mídias" e, portanto, permitem o aumento da "compreensão, autonomia, fluência e criticidade, de modo a se expressar e partilhar informações, experiências, ideias e sentimentos, e continuar aprendendo" (BRASIL, 2018, p. 87).

Visualizando este cenário no qual o reconto tem potencial para o cumprimento das habilidades e competências apresentadas, percebe-se igualmente seu potencial para provocar, despertar nos alunos/crianças esse olhar próprio de questionamento a caminho da aceitação de seu pertencimento étnico-racial e o seu desenvolvimento como sujeitos contrários a quaisquer formas de discriminação e preconceito.

Deste modo, verifica-se que o reconto propriamente dito, a despeito de contribuir para o desenvolvimento das capacidades de leitura e escrita, transpõe outros limites, posto que sua essência proporciona aos alunos/crianças, além das habilidades necessárias para o desenvolvimento da leitura e escrita, o saber expressar, o saber partilhar informações, experiências, ideias e sentimentos (NUNES, 2018) e, quando articulado à LIN, proporciona o continuar aprendendo, uma vez que ensina a valorizar as diversas manifestações culturais, a posicionar-se ética e criticamente em relação às atitudes discriminatórias que têm a intenção de ferir os direitos individuais e coletivos e, ao mesmo tempo, aproxima as crianças dos títulos, personagens e enredos contemplados na Literatura Infantil Negra. 


\section{Revista de Estudos em Educação e Diversidade}

REEP

\section{Considerações Finais}

Analisando a discussão estabelecida neste trabalho, é possível perceber que o reconto se mostra favorável para o objetivo traçado quanto à (re)construção da identidade da criança negra, visto que, ao apresentar as suas características (leitura, releitura, escrita, oralização), bem como as habilidades e algumas competências previstas na BNCC em relação à disciplina de Língua Portuguesa, para os anos iniciais do Ensino Fundamental, notou-se como ele, o reconto, se harmoniza sensivelmente com o desenvolvimento das mesmas e, particularmente, quando articulado à LIN adquire uma configuração metodológica capaz de proporcionar um amadurecimento tanto intelectual quanto pessoal dos assuntos que lhe sejam subordinados.

Este amadurecimento, portanto, pode resultar em mudanças de atitude, inclusive, para a (re)construção identitária, uma vez que os alunos/crianças negros, vendo-se representados por personagens semelhantes a si, em vários contextos de maneira positiva, podem vir a se sentir provocados a se reconhecerem e se autoafirmarem pelo seu pertencimento étnico-racial.

Deste modo, resgatando a ideia de que os alunos/crianças quando ouvem histórias passam a apropriar-se de elementos delas para si (MATOS; SORSY, 2009; NUNES 2018), no ato de recontá-las estarão fortalecendo esses elementos em seus discursos, podendo então incorporá-los aos seus contextos de vivência, o que resvalará não somente na tomada de consciência, mas fará germinar desde o início da educação básica tudo aquilo que preveem as Diretrizes para a Educação das Relações Étnico-raciais a respeito da reeducação cultural da sociedade brasileira.

Para finalizar, é ponto de reconhecimento as prováveis lacunas contidas no presente estudo, porém, a despeito disso, alimenta-se a expectativa de que a discussão aqui iniciada, os aspectos devidamente expostos e os caminhos trilhados em torno do reconto possam encontrar eco, mostrando-se eficientes e eficazes em contextos reais de ensino porque é evidente haver falhas nas relações de ensino-aprendizagem que precisam ser denunciadas, reavaliadas e, se possível, reconstruídas.

\section{Referências}

BERND, Zilá. Introdução à literatura negra. São Paulo: editora Brasiliense, 1988.

BRASIL. Conselho Nacional de Educação; Conselho Pleno. Resolução no 1, de 17 de junho de 2004. Institui Diretrizes Curriculares Nacionais para a Educação das Relações Étnico- 
Raciais e para o Ensino de História e Cultura Afro-Brasileira e Africana. Disponível em: http://portal.mec.gov.br/cne/arquivos/pdf/res012004.pdf. Acesso em: 27 ago. 2020.

Base Nacional Comum Curricular (BNCC). Ministério da Educação, 2018. Disponível em: http://basenacionalcomum.mec.gov.br/. Acesso em: 29 ago. 2020.

CAMPOS, Wagner Ramos. Os griôs aportam na escola: por uma abordagem metodológica da literatura infantil negra nos Anos Iniciais do Ensino Fundamental. 2016. Dissertação (Mestrado em Educação) - Universidade Federal do Rio Grande do Norte. Natal, RN, 2016.

CASTILHO, Suely Dulce de. A representação do negro na literatura brasileira: novas perspectivas. Olhar de professor, Ponta Grossa, v. 7, n. 1, p. 103-113, 2004.

DOMINGUES, Petrônio. Movimento da negritude: uma breve reconstrução histórica. Mediações. Revista Ciências Sociais, Londrina, v. 10, n. 1, p. 25-40, jan-jun., 2005.

DUARTE, Eduardo de Assis. Literatura afro-brasileira: um conceito em construção. Estudos de Literatura Brasileira Contemporânea, v. 1, p. 11-24, 2008.

Literatura e afrodescendência. Portal de Literatura Afro-brasileira - Faculdade de Letras/UFMG. Disponível em: http://www.letras.ufmg.br/literafro/artigos/artigos-teoricoconceituais/150-eduardo-de-assis-duarte-literatura-e-afrodescendencia. Acesso em: 05 set. 2020 .

GOMES JUNIOR, Jorge Luiz. A magia do contar e recontar histórias ancestrais na literatura infantil e juvenil brasileira: recriando valores. 2014. Dissertação (Mestrado em Relações Étnico-raciais). Centro Federal de Educação Tecnológica Celso Suckow da Fonseca (CEFET). Rio de Janeiri, 2014.

IANNI, Octavio. Literatura e consciência. Revista do Instituto de Estudos Brasileiro, SP, 28, p. 91-99, 1988.

JOVINO, Ione da Silva. Literatura infanto-juvenil com personagens negros no Brasil. In: SOUZA, Forentina; LIMA, Maria Nazaré (Orgs.). Literatura afro-brasileira. Salvador: Centro de Estudos Afro-Orientais. Brasília: Fundação Cultural Palmares, 2006. p. 180-220.

Personagens negras na literatura infantil brasileira de 1980 a 2000: revisitando o tema. $38^{a}$ Reunião Nacional Anped. Democracia em risco: pesquisa e a pós-graduação em contexto de resistência. 38, out., São Luiz, MA, 2017. Anais [...]. 38, São Luiz, MA, p. 1-17. 2017.

LAJOLO, Marisa Philbert. A figura do negro em Monteiro Lobato. Presença Pedagógica, Belo Horizonte, v. 04, n. 23, p. 21-31, 1998.

LIMA, Carina Bertozzi de. Literatura negra: uma outra história. Terra Roxa e Outras Terras. Revista de Estudos Literários. v. 17-A. dez., p. 67-77, 2009.

MATOS, Gislayne Avelar; SORSY, Inno. Ofício do contador de histórias: perguntas e respostas, exercícios práticos e um repertório para encantar. São Paulo: Martins Fontes, 2009. 


\section{Revista de Estudos em Educação e Diversidade}

MÉRIAN, Jean-Yves. O negro na literatura brasileira versus uma literatura afro-brasileira: mito e literatura. Navegações, v. 1, n. 1, p. 50-60. mar., 2008.

MORAES, Pedro Rodolfo Bodê de. O jeca e a cozinheira: raça e racismo em Monteiro Lobato. Revista de Sociologia e Política, n. 08, p. 99-112, 1997.

NUNES, Sheila Maroccolo. Contação de histórias e empatia: relações estabelecidas a partir do reconto de crianças. 2018. Dissertação (Mestrado em processos de desenvolvimento Humano e Saúde) - Universidade de Brasília, Brasília, 2018.

PAIVA, Núbia Silva Guimarães Paiva; NUNES, Liliane dos Guimarães Alvin; DE DEUS, Maria Ferreira. A construção da identidade da criança na educação infantil numa perspectiva histórico-cultural. Olhares \& Trilhas. Uberlândia, ano XI, n. 11, p. 85-96, 2010.

PEREIRA, Edmilson de Almeida. Panorama da literatura afro-brasileira. Callaloo, v. 18, n. 4, p. 1035-1040, 1995.

PEREIRA, Luena Nascimento Nunes. Literatura negra infanto-juvenil: discursos afrobrasileiros em construção. Interseções [Rio de Janeiro], v. 18, n. 2, p. 431-457, 2016.

SILVA, Celso Sisto. Bô sukuta! Kada kin ku su manera: as junbai tradicionais africanas recriadas na literatura infantojuvenil brasileira, eué! 2012. Tese (Doutorado em Letras). Faculdade de Letras. Porto Alegre, Pontifícia Universidade Católica do Rio Grande do Sul, Porto Alegre, 2012.

SILVA, Tomaz Tadeu da. Documentos de identidade: uma introdução às teorias do currículo. 2. ed. Belo Horizonte: Autêntica, 2002.

SOUZA, Florentina. Literatura afro-brasileira: algumas reflexões. Revista Palmares. Brasília, v. 1, p. 64-72, 2006.

Recebido em: 20 de setembro de 2021.

Aprovado em: 21 de dezembro de 2021. 